\title{
Overexpression of phosphoprotein enriched in astrocytes 15 reverses the damage induced by propofol in hippocampal neurons
}

\author{
FENG XIAN $^{1}$, QIFANG $\mathrm{LI}^{2}$ and ZUPING CHEN ${ }^{1}$ \\ ${ }^{1}$ Department of Anesthesiology, The First People's Hospital of Changzhou, \\ The Third Affiliated Hospital of Soochow University, Changzhou, Jiangsu 213000; \\ ${ }^{2}$ Department of Anesthesiology, Shanghai Ninth People's Hospital, Shanghai 200011, P.R. China
}

Received August 12,2018; Accepted May 20, 2019

DOI: $10.3892 / \mathrm{mmr} .2019 .10412$

\begin{abstract}
Propofol is a general anesthetic used in surgical operations. Phosphoprotein enriched in astrocytes 15(PEA15) was initially identified in astrocytes. The present study examined the role of PEA15 in the damage induced by propofol in hippocampal neurons. A model of hippocampal neuron damage was established using $50 \mu \mathrm{mol} / 1$ propofol. Cell viability, proliferation and apoptosis of hippocampal neurons were tested by Cell Counting Kit- 8 and flow cytometry. Western blotting and reverse transcription-quantitative polymerase chain reaction analysis were performed to measure the expression levels of PEA15, and additional factors involved in apoptosis or in the signaling pathway downstream of PEA15. The present results suggested that propofol significantly decreased PEA15 expression levels in hippocampal neurons. Furthermore, overexpression of PEA15 significantly increased the cell viability and cell proliferation of cells treated with propofol. Additionally, PEA15 overexpression decreased apoptosis, which was promoted by propofol. Treatment with propofol significantly decreased the protein expression levels of pro-caspase-3, B-cell lymphoma-2, phosphorylated extracellular signal-regulated kinases (ERK)1/2, ribosomal S6 kinase 2 (RSK2) and phosphorylated cAMP responsive element binding protein 1 (CREB1). However, propofol upregulated active caspase- 3 and Bax expression levels. Notably, PEA15 overexpression was able to reverse the effects of propofol. Collectively, overexpression of PEA15 was able to attenuate the neurotoxicity of propofol in rat hippocampal neurons by increasing proliferation and repressing apoptosis via upregulation of the ERK-CREB-RSK2 signaling pathway.
\end{abstract}

Correspondence to: Dr Zuping Chen, Department of Anesthesiology, The First People's Hospital of Changzhou, The Third Affiliated Hospital of Soochow University, 185 Juqian Road, Changzhou, Jiangsu 213000, P.R. China

E-mail: chenzuping_zpcmd@163.com

Key words: propofol, phosphoprotein enriched in astrocytes 15, hippocampal neurons, neurotoxicity

\section{Introduction}

Annually, in the USA, approximately six million children require general anesthesia $(1,2)$. Furthermore, in China, the number of children requiring anesthetics is increasing (3). The human brain develops rapidly between the embryonic stage and 2 years after birth. During this period the number of neurons increases, and large quantities of axons, dendrites and synapses are formed (4-6). Previous clinical studies have demonstrated that anesthesia and surgery may lead to cognitive impairment $(7,8)$. Therefore, decreasing the brain neuronal damage caused by narcotic drugs is becoming an increasingly popular research topic.

A number of previous studies identified that inhalable narcotic drugs, including midazolam, propofol, isoflurane and sevoflurane, are used in newborns (9-12). Propofol is a general anesthetic used in surgical operations. Previous studies demonstrated that propofol may induce neurotoxicity in the brains of newborn animals (13-16). In addition, previous studies identified that propofol-induced apoptosis in numerous types of cells associated with neurons (17-19). Therefore, it is crucial to identify novel effective strategies to decrease the neurotoxicity of propofol in the developing brain.

Phosphoprotein enriched in astrocytes 15 (PEA15) is a phosphoprotein that was initially identified in astrocytes (20). PEA15 is known to mediate the signal transduction pathway; PEA15 serves as a signal connection point, thus possessing the potential to directly regulate cell behavior (21). Previous studies demonstrated that PEA15 serves roles in numerous processes, including tumor progression, diabetes, metabolic disorders and nervous system diseases (22-26). However, at present, to the best of the authors' knowledge, the effect of PEA15 on propofol-induced hippocampal nerve injury has not been investigated.

In the present study, propofol was used to damage rat hippocampal neurons. Furthermore, the effect and potential molecular mechanism of PEA15 on propofol-induced hippocampal neuronal cell damage were examined by Cell Counting Kit-8 (CCK-8), flow cytometry, western blotting and reverse transcription-quantitative polymerase chain reaction (RT-qPCR) analysis.

\section{Materials and methods}

Animals. Pregnant Sprague-Dawley (SD) rats (3 months old; embryonic age E18; weight: 200-230 g) were purchased from 
Shanghai SLAC Laboratory Animal Co., Ltd. (Shanghai, China). The rats were housed in cages at $22 \pm 1^{\circ} \mathrm{C}$. The animals had free access to food and water, with a constant humidity $(50 \pm 10 \%)$ and with a $12 \mathrm{~h} \mathrm{light/dark} \mathrm{cycle.} \mathrm{The} \mathrm{animal} \mathrm{experi-}$ mental research was approved by the Ethics Committee of The First People's Hospital of Changzhou, The Third Affiliated Hospital of Soochow University (Changzhou, China).

Isolation of hippocampal neurons. The extraction and cultivation methods of the neurons were performed as previously described $(27,28)$. In total, 5 newborn SD rats ( 3 male and 2 female; weight, 5.0-6.0 g) were sacrificed by cervical dislocation, within $24 \mathrm{~h}$ following birth. A solution of $75 \%$ ethanol was used to disinfect the fetal rats in sterile trays. Subsequently, the rats were guillotined. The brain was removed using bent tweezers and placed in a precooled Hank's balanced salt solution and the hippocampus was separated from the brain. Subsequently, the hippocampus was digested using $2 \%$ trypsin for $15 \mathrm{~min}$ at $37^{\circ} \mathrm{C}$ in a cell incubator with $5 \% \mathrm{CO}_{2}$. The digestion was stopped by adding neurobasal medium (Thermo Fisher Scientific, Inc., Waltham, MA, USA) containing $10 \%$ fetal bovine serum (Cellbio, Shanghai, China). The hippocampal neurons were obtained and maintained in an incubator at $37^{\circ} \mathrm{C}$ with $5 \% \mathrm{CO}_{2}$. The morphology of the cells was observed daily using a TMM-220 inverted light microscope (magnification, x200; Shanghai Tianxing Instrument Co., Ltd., Shanghai, China).

Cell treatment and transfection. Propofol was purchased from Fresenius Kabi Austria GmbH (Graz, Austria). As previously described $(29,30)$, the hippocampal neurons were exposed to $50 \mu \mathrm{mol} / \mathrm{l}$ propofol for $0,6,12$ and $24 \mathrm{~h}$. Subsequently, cells were transfected with $50 \mathrm{nM}$ PEA15 cloned in pcDNA3.1 or empty pcDNA3.1 vectors (Invitrogen; Thermo Fisher Scientific, Inc.) using Lipofectamine ${ }^{\circledR} 2000$ (Thermo Fisher Scientific, Inc.) and cultured for $48 \mathrm{~h}$ at $37^{\circ} \mathrm{C}$. A total of six experimental groups were considered in the present study: Control group (0.1\% PBS), empty-vector group (transfected with pcDNA3.1 vector), PEA15 group (transfected with PEA15), propofol group (treated with $50 \mu \mathrm{mol} / 1$ propofol), empty-vector + propofol group (transfected with pcDNA3.1 empty vector and treated with $50 \mu \mathrm{mol} / 1$ propofol), and PEA15+propofol group (transfected with PEA15 and treated with $50 \mu \mathrm{mol} / 1$ propofol).

Cell viability assay. A CCK-8 (Beyotime Institute of Biotechnology, Haimen, China) assay was conducted to detect the cell viability. A total of $2 \times 10^{3}$ cells $/ \mathrm{ml}$ in logarithmic phase were inoculated in 96-well plates and maintained in an incubator at $37^{\circ} \mathrm{C}$ with $5 \% \mathrm{CO}_{2}$ for $24 \mathrm{~h}$. Subsequently, cells were treated with propofol at $12.5,25$ and $50 \mu \mathrm{mol} / 1$ for $6 \mathrm{~h}$ at $37^{\circ} \mathrm{C}$ and divided into the aforementioned experimental groups, and transferred into the incubator for 6, 12 and $24 \mathrm{~h}$. CCK- 8 reagent was added into each well. Cells were cultured in the incubator at $37^{\circ} \mathrm{C}$ with $5 \% \mathrm{CO}_{2}$ for $2.5 \mathrm{~h}$. An HBS-1096A microplate reader (Nanjing Detie Experimental Equipment Co., Ltd., Nanjing, China) was used to measure the absorbance at $450 \mathrm{~nm}$.

Flow cytometry assay. Cell apoptosis was determined using an Annexin V-fluorescein isothiocyanate (FITC)/propidium iodide (PI) apoptosis detection kit [Hangzhou Multi Sciences (Lianke) Biotech Co., Ltd., Hangzhou, China]. The cells were digested with $0.25 \%$ trypsin (Beyotime Institute of Biotechnology). The supernatant was removed and cells were resuspended in an incubation buffer at a density of $2 \times 10^{5}$ cells $/ \mathrm{ml}$. Annexin V-FITC and PI were added to the cell suspension in the dark at room temperature for $20 \mathrm{~min}$. The CytoFLEX flow cytometer (Beckman Coulter, Inc., Brea, CA, USA) was used to detect cell apoptosis. Cell proliferation was assessed using the CellTrace ${ }^{\mathrm{TM}}$ carboxyfluorescein succinimidyl ester (CFSE) cell proliferation kit (Invitrogen; Thermo Fisher Scientific, Inc.). The cells were digested with $0.25 \%$ trypsin (Beyotime Institute of Biotechnology). The supernatant was removed and cells were resuspended in an incubation buffer at a density of $2 \times 10^{5}$ cells $/ \mathrm{ml}$. The CFSE solution was added to the cell suspension and incubated for $15 \mathrm{~min}$ at room temperature. A CytoFLEX flow cytometer (CytExpert software v1.2; Beckman Coulter, Inc.) was used to measure the cell proliferation.

Western blotting. Subsequent to being treated, cells were lysed with radioimmunoprecipitation assay buffer (Beyotime Institute of Biotechnology). The protein content was analyzed using the Bradford method. A 10\% SDS-PAGE was used to separate $(20 \mu \mathrm{g} / \mathrm{lane})$ proteins, that were transferred onto a polyvinylidene difluoride (PVDF) membrane. The PVDF membrane was sealed and blocked using 5\% non-fat milk at $37^{\circ} \mathrm{C}$ for $1.5 \mathrm{~h}$. Subsequently, the PVDF membrane was incubated with primary antibodies at $4^{\circ} \mathrm{C}$ for $24 \mathrm{~h}$. The following antibodies were used in the present study: Anti-PEA15 [1:800; Cell Signaling Technology (CST), Inc., Danvers, MA, USA; cat. no. 2780], anti-pro-caspase-3 (1:1,000; Abcam, Cambridge, UK; cat. no. ab32150), anti-active caspase-3 (1:600; Abcam; cat. no. ab13847), anti-B-cell lymphoma-2 (Bcl-2; 1:700; Abcam; cat. no. ab59348), anti-apoptosis regulator BAX (Bax; 1:1,000; Abcam; cat. no. ab32503), anti-phosphorylated (p)-extracellular signal-regulated kinases 1/2 (ERK1/2; 1:1,000; CST, Inc.; cat. no. 4370), anti-ERK1/2 (1:600; CST, Inc.; cat. no. 9102), anti-ribosomal S6 kinase 2 (RSK2; 1:500; Abcam; cat. no. ab32133), anti-p-cAMP-response element binding protein 1 (CREB1; 1:800; Abcam; cat. no. ab32096), anti-CREB1 (1:700; Abcam; cat. no. ab32515) and anti- $\beta$-actin (1:5,000; Abcam; cat. no. ab179467). The PVDF membrane was subsequently incubated with Horseradish peroxidase-conjugated secondary antibodies (goat anti-rabbit; cat. no. ab205718; 1:2,000) at room temperature for $1 \mathrm{~h}$. The proteins were detected using enhanced chemiluminescent reagents (Thermo Fisher Scientific, Inc.). The density of bands was determined using the Quantity One software version 2.4 (Bio-Rad Laboratories, Inc., Hercules, CA, USA).

$R T-q P C R$. Total RNA from the neurons was extracted using TRIzol ${ }^{\circledR}$ reagent (Invitrogen; Thermo Fisher Scientific, Inc.). RNA was reverse transcribed to cDNA using an RT kit (HaiGene, Harbin, China) at $37^{\circ} \mathrm{C}$ for $15 \mathrm{~min}$ followed by $85^{\circ} \mathrm{C}$ for $5 \mathrm{sec}$. The ABI 7500 Thermocycler (Applied Biosystems; Thermo Fisher Scientific, Inc.) was used to amplify the cDNA with AceQ qPCR SYBR-Green Master Mix (Vazyme, Piscataway, NJ, USA). qPCR conditions were set as follows: $10 \mathrm{~min}$ pretreatment at $95^{\circ} \mathrm{C}, 96^{\circ} \mathrm{C}$ for $15 \mathrm{sec}, 63^{\circ} \mathrm{C}$ for $45 \mathrm{sec}$ 

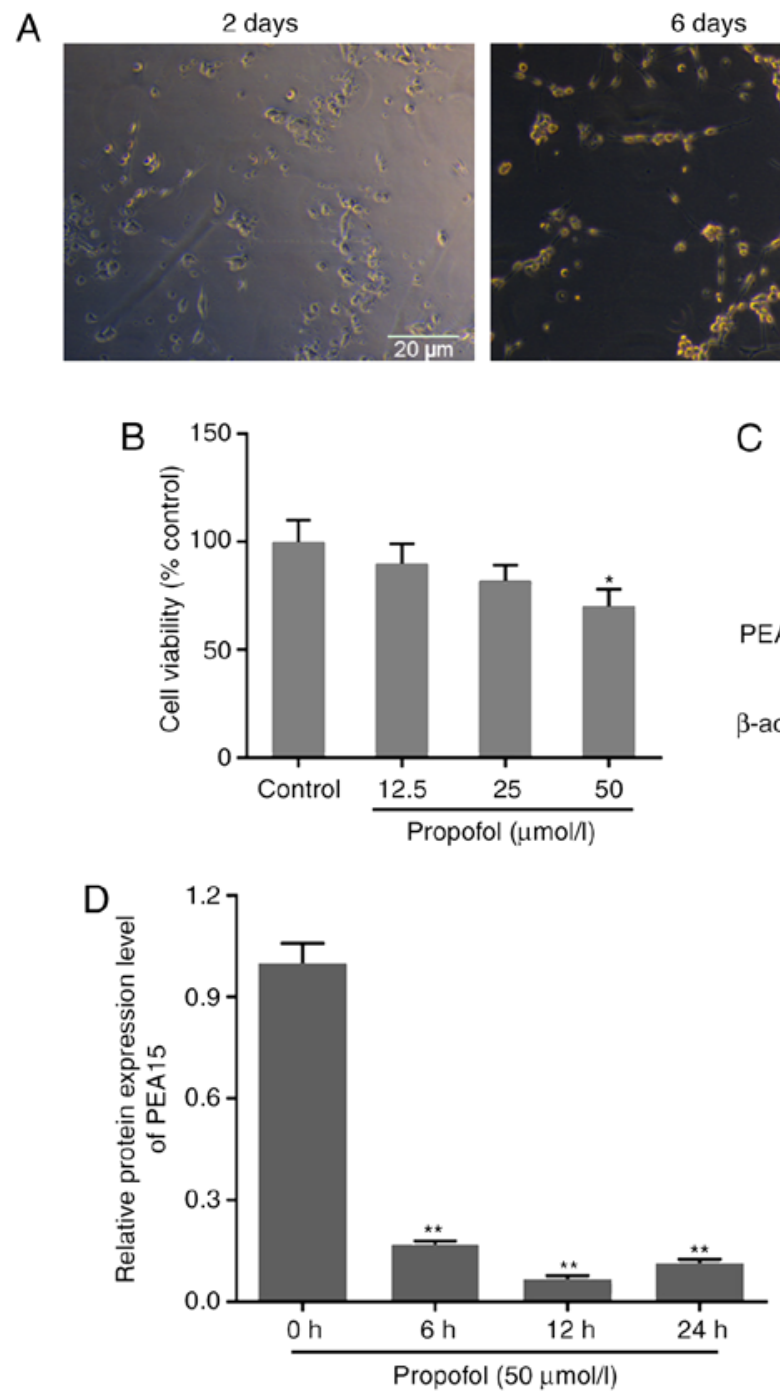

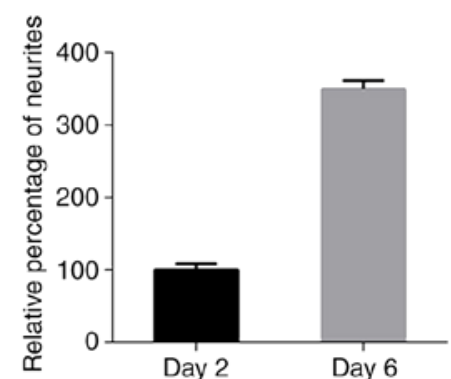

C
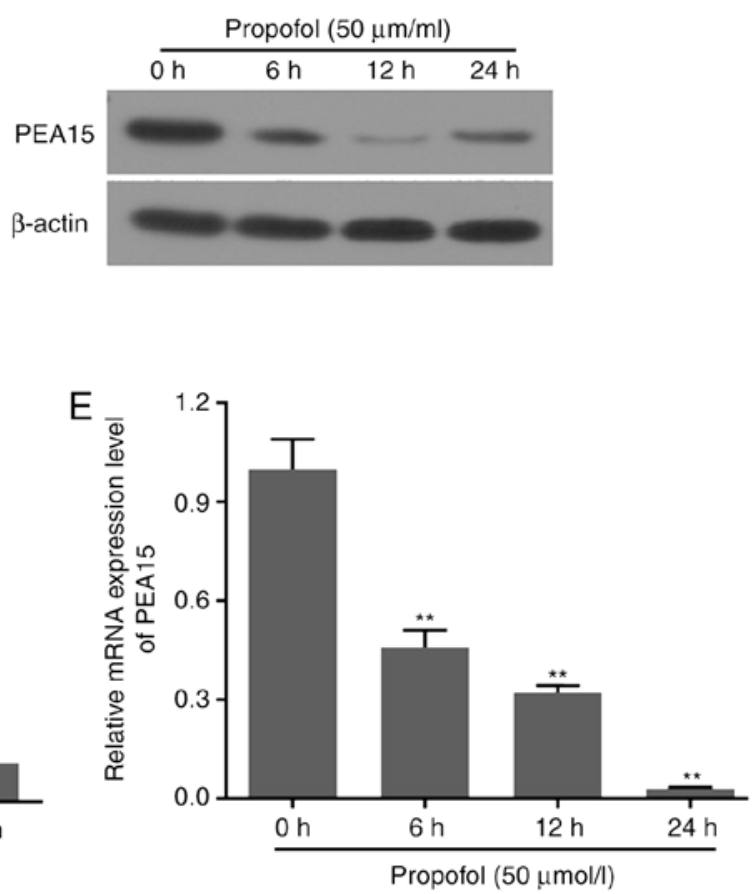

Figure 1. Propofol inhibits the expression level of PEA15 in hippocampal neurons. (A) Hippocampal neurons were cultured in an incubator at $37^{\circ} \mathrm{C}$ with $5 \% \mathrm{CO}_{2}$ for 2 and 6 days. The morphology of hippocampal neurons was observed using an inverted microscope. (B) Effect of different concentrations of propofol $(12.5,25$ and $50 \mu \mathrm{mol} / 1)$ on cell viability following treatment for $6 \mathrm{~h}$. ${ }^{*} \mathrm{P}<0.05$ vs. control. Following treatment with $50 \mu$ mol/1 propofol for $0,6,12$ and $24 \mathrm{~h}$, the protein expression level of PEA15 was determined by (C) western blotting and (D) densitometric analysis. (E) mRNA expression level of PEA15 was measured by reverse transcription-quantitative polymerase chain reaction. ${ }^{* *} \mathrm{P}<0.01 \mathrm{vs} .0 \mathrm{~h}$. PEA15, phosphoprotein enriched in astrocytes 15 .

(35 cycles) and a final extension at $75^{\circ} \mathrm{C}$ for $10 \mathrm{~min} . \beta$-actin was used as the reference gene. The primers used were purchased from Shanghai ShineGene Molecular Biotech, Inc. (Shanghai, China) and were the following: PEA15 (forward, 5'-CCTGAC CAACAACATCACCC-3' and reverse, 5'-GATCTTCAGCAC ACGGGTTC-3'), Bcl-2 (forward, 5'-GCCTTCTTTGAGTTC GGTGG-3' and reverse), Bax (forward, 5'-GAGACACCTGAG CTGACCTT-3' and reverse, 5'-CGTCTGCAAACATGTCA GCT-3') and $\beta$-actin (forward, 5'-CAACATGGATGAGCGGA AGG-3' and reverse, 5'-GCAGTGTAGCAGCATCGAAA-3'). The $2^{-\Delta \Delta \mathrm{Cq}}$ method was used to calculate gene expression levels (31).

Statistical analysis. SPSS (version 20; IBM Corp., Armonk, NY, USA) software was used for statistical analysis. The data are presented as the mean \pm standard deviation. The experiments were independently repeated at least three times. The experimental data were analyzed by one-way analysis of variance with Tukey's post hoc test.
$\mathrm{P}<0.05$ was considered to indicate a statistically significant difference.

\section{Results}

Propofol inhibits the expression level of PEA15 in hippocampal neurons. Following hippocampal neuron isolation, the cells were cultured for 2 days. The neurons presented 2-3 neurites, and were flat and multilateral. Following 6 days of incubation, the number of neurites increased, and the cells interconnected with each other through the neurites. Notably, the majority of the cells aggregated and exhibited a visible halo surrounding the cells (Fig. 1A).

Cell viability decreased following treatment with propofol at $12.5,25$ and $50 \mu \mathrm{mol} / 1$ for $6 \mathrm{~h}$. The decrease in cell viability was significant in the $50 \mu \mathrm{mol} / 1$ group (Fig. 1B). Therefore, $50 \mu \mathrm{mol} / 1$ propofol was selected as the working concentration. Western blotting and RT-qPCR assays were performed to examine the effects of propofol on the expression level 
A

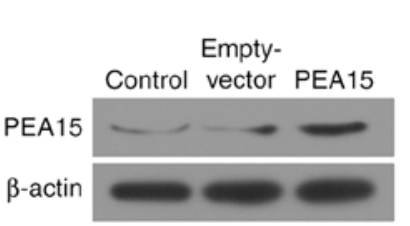

B

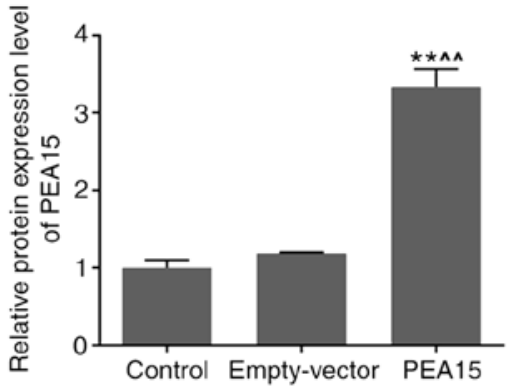

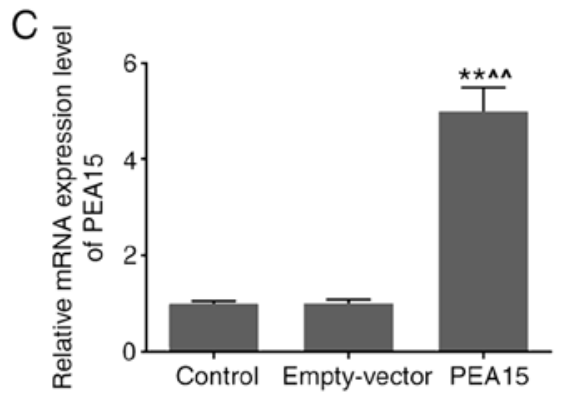
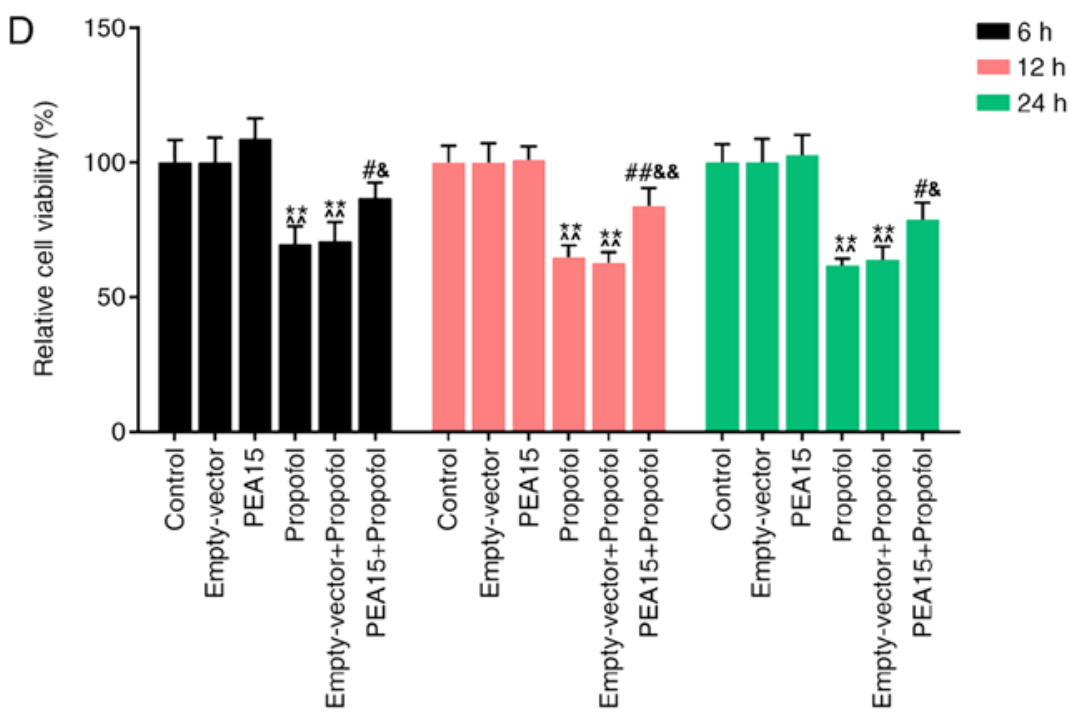

Figure 2. Overexpression of PEA15 reverses the decreased viability of hippocampal neurons induced by propofol. Hippocampal neurons were transfected with PEA15 (PEA15 group) or pcDNA3.1 (empty-vector group). (A) Western blotting and (B) subsequent quantification were conducted to detect the protein expression level of PEA15. (C) Reverse transcription-quantitative polymerase chain reaction was performed to detect the mRNA expression level of PEA15. (D) Hippocampal neurons were treated with $0.1 \%$ PBS (control group), transfected with pcDNA3.1 (empty-vector group) or PEA15 (PEA15 group), treated with $50 \mu \mathrm{mol} / 1$ propofol (propofol group), transfected with pcDNA3.1 and treated with $50 \mu \mathrm{mol} / 1$ propofol (empty-vector + propofol group), and transfected with PEA15 and treated with $50 \mu \mathrm{mol} / 1$ propofol (PEA15 + propofol group). A Cell Counting Kit- 8 assay was used to measure the cell viability.** $\mathrm{P}<0.01$ vs. control; ${ }^{\wedge \wedge} \mathrm{P}<0.01$ vs. empty-vector; ${ }^{\#} \mathrm{P}<0.05,{ }^{\# \#} \mathrm{P}<0.01$ vs. propofol; ${ }^{\&} \mathrm{P}<0.05$, ${ }^{\& \&} \mathrm{P}<0.01$ vs. empty-vector + propofol. PEA 15 , phosphoprotein enriched in astrocytes 15 .

of PEA15 in hippocampal neurons. The western blotting suggested that the protein expression level of PEA15 was decreased following treatment with propofol for 6,12 and $24 \mathrm{~h}$. Notably, the protein expression level of PEA15 was lower at $12 \mathrm{~h}$ compared with $24 \mathrm{~h}$; however, the difference was not significant (Fig. 1C and D). Furthermore, propofol significantly decreased the mRNA expression level of PEA15 in a time-dependent manner (Fig. 1E).

Overexpression of PEA15 reverts the decreased viability of hippocampal neurons induced by propofol. The transfection efficiency of PEA15 in hippocampal neurons was examined by western blotting and RT-qPCR analysis. The western blotting results demonstrated that the protein expression level of PEA15 was significantly increased following transfection with PEA15 (Fig. 2A and B). Additionally, the mRNA expression level of PEA15 was consistent with the protein expression level (Fig. 2C).

CCK-8 was used to test the effects of PEA15 and propofol on the viability of hippocampal neurons. The results suggested that propofol significantly decreased cell viability, compared with the control and empty-vector groups. The cell viability was unaffected following transfection of PEA15 alone.
However, the cell viability in the PEA15 + propofol group was significantly increased compared with the propofol and empty-vector + propofol groups (Fig. 2D).

Overexpression of PEA15 represses the propofol-induced apoptosis of hippocampal neurons. The flow cytometry results suggested that propofol significantly promoted cell apoptosis. However, PEA15 overexpression was able to decrease the apoptosis of cells treated with propofol compared with the propofol and empty-vector + propofol groups (Fig. 3).

Overexpression of PEA15 reverts the proliferation of hippocampal neurons inhibited by propofol. The cell proliferation assay suggested that propofol significantly decreased the proliferation of hippocampal neurons. In addition, transfection of PEA15 was sufficient to increase the cell proliferation of cells treated with propofol compared with the propofol and empty-vector + propofol groups (Fig. 4).

PEA15 and propofol regulate apoptosis-associated factors in hippocampal neurons. Western blotting and RT-qPCR analysis were performed to investigate the effects of PEA15 and propofol on apoptosis-associated factors. The western blotting results 
A
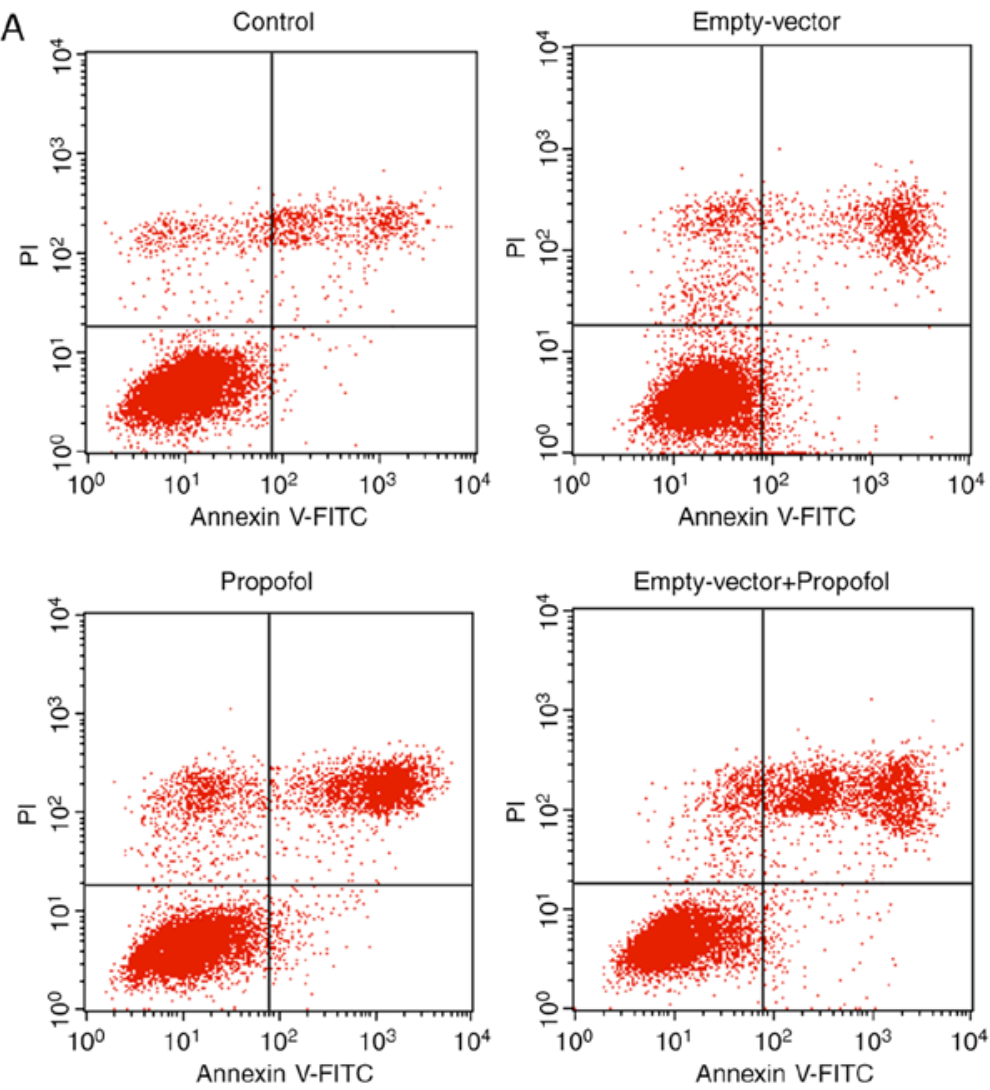
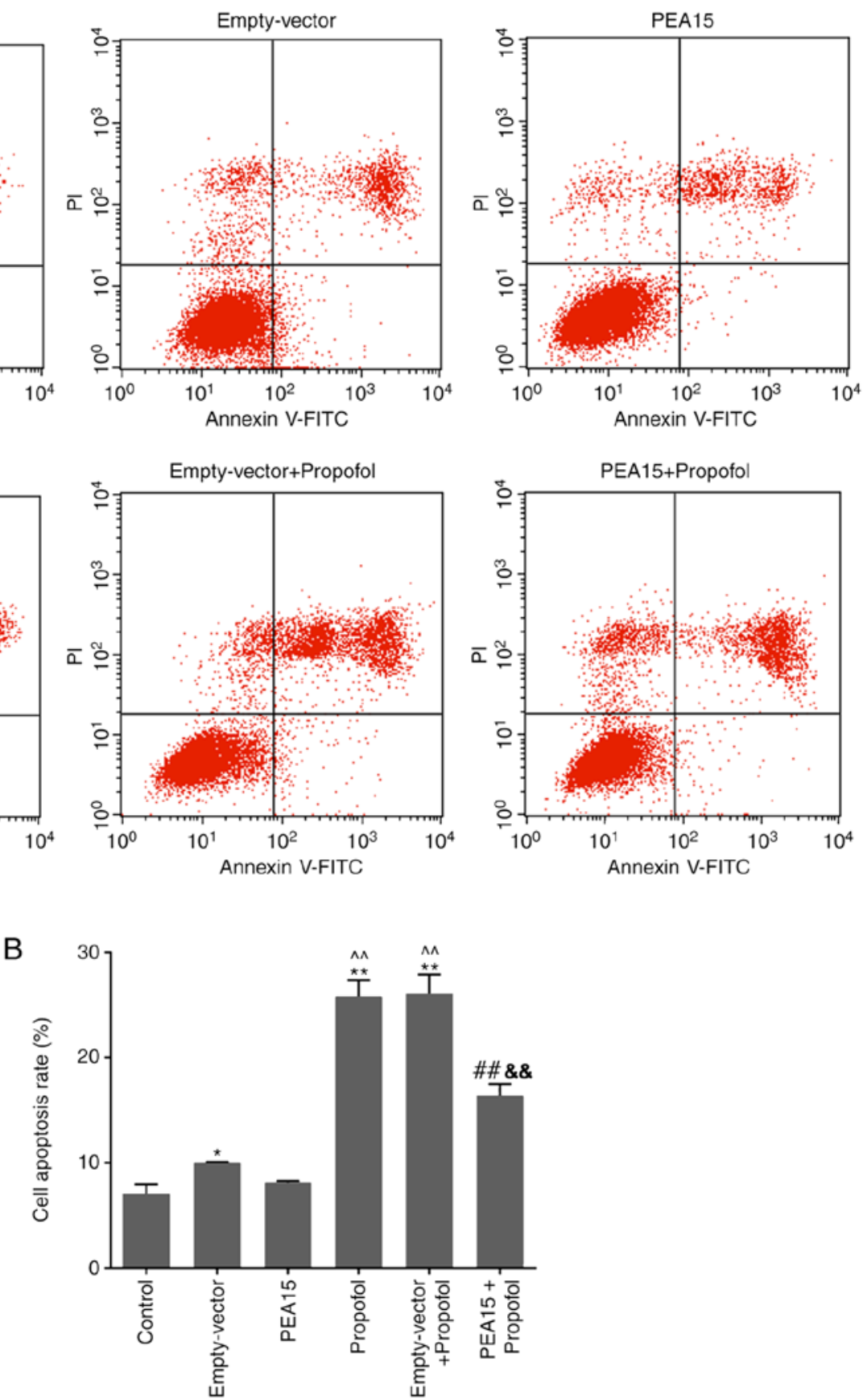

Figure 3. Overexpression of PEA15 represses the propofol-induced apoptosis of hippocampal neurons. (A) An Annexin V-FITC/PI apoptosis detection kit was used to detect apoptosis of the hippocampal neurons. (B) Bar graph indicates the apoptosis of hippocampal neurons among the groups. ${ }^{*} \mathrm{P}<0.05$, ${ }^{* *} \mathrm{P}<0.01$ vs. control; ${ }^{\wedge} \mathrm{P}<0.01$ vs. empty-vector; ${ }^{\# \#} \mathrm{P}<0.01$ vs. propofol; \&\& $\mathrm{P}<0.01$ vs. empty-vector + propofol. $\mathrm{PEA} 15$, phosphoprotein enriched in astrocytes 15 ; FITC, fluorescein isothiocyanate; PI, propidium iodide.

suggested that treatment with propofol promoted the protein expression levels of active caspase-3 and Bax (Fig. 5A and B), and led to downregulation of pro-caspase- 3 and $\mathrm{Bcl}-2$ protein expression levels (Fig. 5A and C). By analyzing the protein and the mRNA expression levels of Bax and Bcl-2, it was identified that the $\mathrm{Bax} / \mathrm{Bcl}-2$ ratio was significantly increased following treatment with propofol (Fig. 5D and E). Notably, PEA15 overexpression led to opposite effects.

PEA15 and propofol regulate ERK-CREB-RSK2 signaling in hippocampal neurons. Western blotting was conducted to determine the protein expression levels of ERK1/2,
p-ERK1/2, p-CREB1, CREB1 and RSK2, in order to examine the molecular mechanisms of PEA15 and propofol on hippocampal neurons. The present results suggested that propofol decreased the protein expression levels of $\mathrm{p}$-ERK1/2, p-CREB1 and RSK2 (Fig. 6A and B). Additionally, it was identified that the ratios between the phosphorylated proteins p-ERK1/2 and p-CREB1, and the respective non-phosphorylated proteins ERK1/2 and CREB1, were significantly decreased (Fig. 6C and D) when cells were treated with propofol. Furthermore, PEA15 promoted the protein expression levels of p-ERK1/2, RSK2 and p-CREB1 in the hippocampal neurons that were treated with propofol. Notably, the protein 

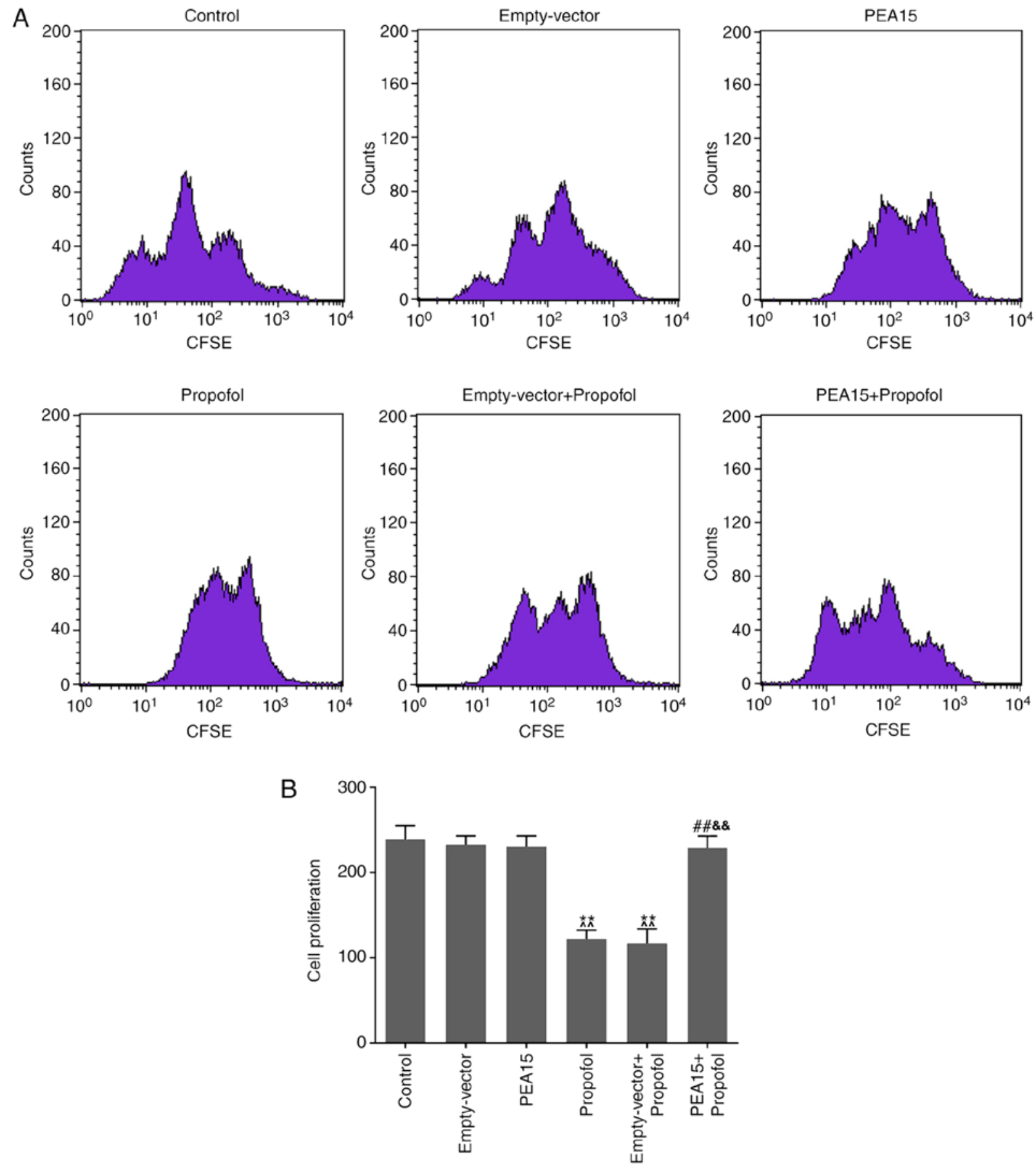

Figure 4. Overexpression of PEA15 reverts the proliferation of hippocampal neurons inhibited by propofol. (A) A CellTrace ${ }^{\mathrm{TM}}$ CFSE cell proliferation kit was used to test the proliferation of hippocampal neurons. (B) Bar graph indicates the proliferation of hippocampal neurons among groups. ${ }^{* *} \mathrm{P}<0.01$ vs. control; ${ }^{\wedge} \mathrm{P}<0.01$ vs. empty-vector; ${ }^{\# \#} \mathrm{P}<0.01$ vs. propofol; \&\& $\mathrm{P}<0.01$ vs. empty-vector + propofol. $\mathrm{PEA} 15$, phosphoprotein enriched in astrocytes 15 ; CFSE, carboxyfluorescein succinimidyl ester.

expression levels of ERK1/2 and CREB1 among groups were not significantly affected.

\section{Discussion}

The majority of cultured hippocampal neurons derive from the hippocampus of neonatal rats, as suckling mice gain an advantage in finding a location to feed $(32,33)$. A previous study identified that hippocampal neurons cultured at day 6 are similar to neurons of a developing human brain (34). During this period, neurons are sensitive to external stimuli, including neurotoxicity caused by anesthetics (34). Therefore, in the present study, primary hippocampal neurons were extracted from neonatal rats and used as a model of developing neurons. Following 6 days of culturing, the cell morphology remained stable and the neurons were treated with propofol.

Accumulating evidence suggested that propofol was neurotoxic in vitro (35-37). Monni et al (36) observed that propofol promoted cell death in rat hypoglossal motoneurons. Yan et al (37) demonstrated that propofol induced apoptosis 

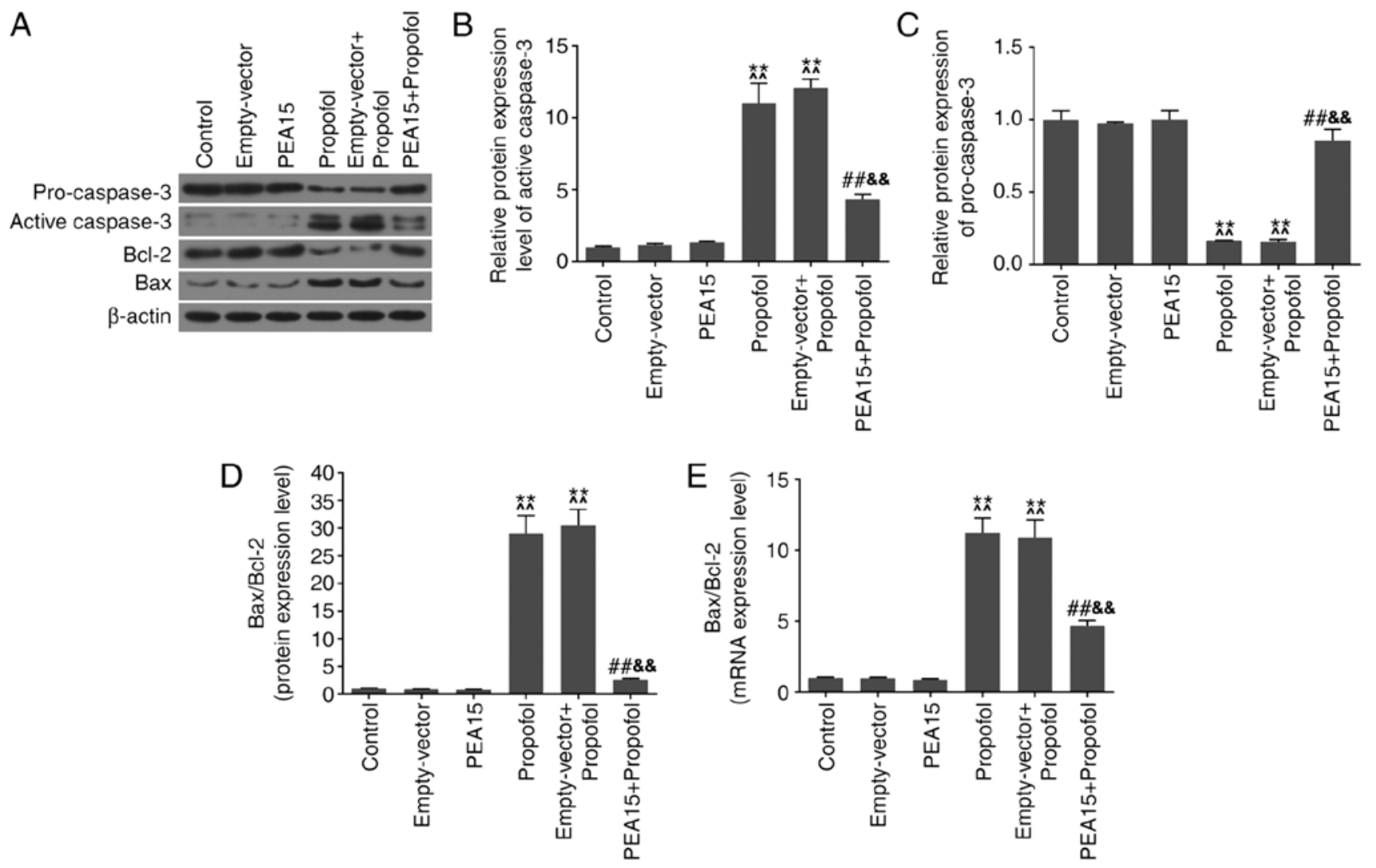

Figure 5. PEA15 and propofol regulate apoptosis-associated factors in hippocampal neurons. (A) Protein expression levels of pro-caspase-3, active caspase-3, Bcl-2 and Bax were determined by western blotting. Densitometric analysis for the protein expression levels of (B) active caspase-3, (C) pro-caspase-3 and (D) Bax/Bcl-2 ratio. (E) mRNA expression levels of Bcl-2 and Bax were assessed by reverse transcription-quantitative polymerase chain reaction assay. ${ }^{* *} \mathrm{P}<0.01$ vs. control; ${ }^{\wedge} \mathrm{P}<0.01$ vs. empty-vector; ${ }^{\# \#} \mathrm{P}<0.01$ vs. propofol; ${ }^{\&} \& \mathrm{P}<0.01$ vs. empty-vector + propofol. PEA15, phosphoprotein enriched in astrocytes 15 ; Bcl-2, B-cell lymphoma-2; Bax, apoptosis regulator BAX.

of hippocampal neurons in newborn mice. Furthermore, numerous previous studies demonstrated that propofol is a potent inducer of neuronal damage $(35,38,39)$. Similar to previous studies, the present results suggested that propofol significantly decreased the viability and proliferation of neuronal cells, promoting cell apoptosis. Therefore, in the present study, treatment with propofol was used as a model for damaging neuronal cells.

A recent study demonstrated that the expression of PEA15 was downregulated in diabetic SD rats, promoting middle cerebral artery occlusion (25). A previous study demonstrated that overexpression of PEA15 decreased glucose deprivation-induced cell death in neurons (40). Therefore, it was hypothesized that the overexpression of PEA15 may decrease the neurotoxicity of propofol, and that PEA15 and propofol may be associated in hippocampal neurons. As hypothesized, the experimental results suggested that propofol significantly decreased PEA15 expression. Furthermore, the CCK-8 and flow cytometry results suggested that PEA15 overexpression significantly increased the viability and proliferation of neurons, and decreased the apoptosis of neuronal cells, reverting the effects of propofol. The present results suggested that overexpression of PEA15 conferred a neuroprotective effect on propofol-induced neuronal damage by promoting proliferation and decreasing apoptosis.

In order to investigate the mechanisms underlying PEA15 and propofol in neuronal cells, the protein expression levels of apoptosis-associated factors, including pro-caspase-3, active caspase-3, Bcl-2 and Bax, were examined by western blotting and RT-qPCR analysis. Liang et al (35) demonstrated that propofol induced apoptosis of the developing neurons by upregulating the protein expression levels of cleaved-caspase-3 and $\mathrm{Bax}$, and by downregulating the Bcl-2 protein expression level. Similarly, the present results demonstrated that propofol significantly increased the protein expression levels of active caspase- 3 and Bax, and decreased pro-caspase- 3 and Bcl-2 expression. Furthermore, Ahn et al (22) observed that PEA-15 increased Bcl-2 and pro-caspase- 3 protein expression levels, and decreased Bax and cleaved-caspase-3 protein expression levels in neuroblastoma cells treated with 1-methyl-4-phenylpyridinium. The present study demonstrated that the overexpression of PEA15 in neurons treated with propofol, increased the protein expression levels of pro-caspase-3 and Bcl-2, and Bax and cleaved-caspase-3 expression levels were downregulated. The present results suggested that overexpression of PEA15 decreased the apoptotic effects induced by propofol in nerve cells by upregulating pro-caspase-3 and Bcl-2, and by downregulating active caspase-3 and Bax.

ERK-CREB signaling regulates cell growth and apoptosis of rat hippocampal neurons (41-43). Furthermore, RSK2 was observed to be involved in the ERK pathway in the hippocampus (44). Kozinn et al (45) demonstrated that propofol inhibited the ERK-CREB pathway in hippocampal 
A
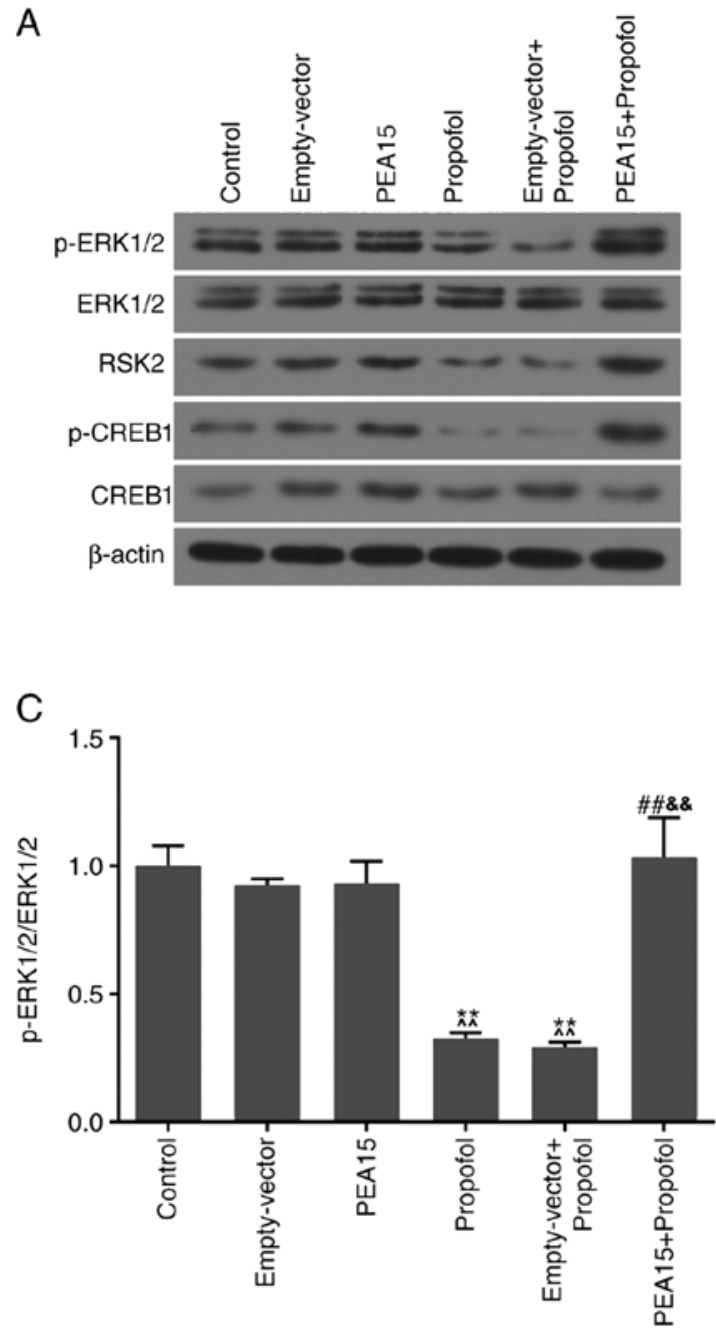

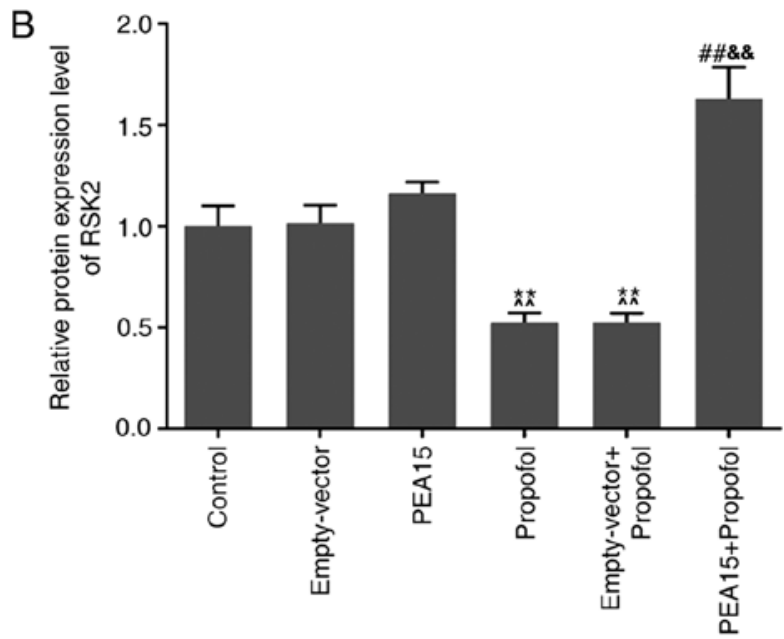

D

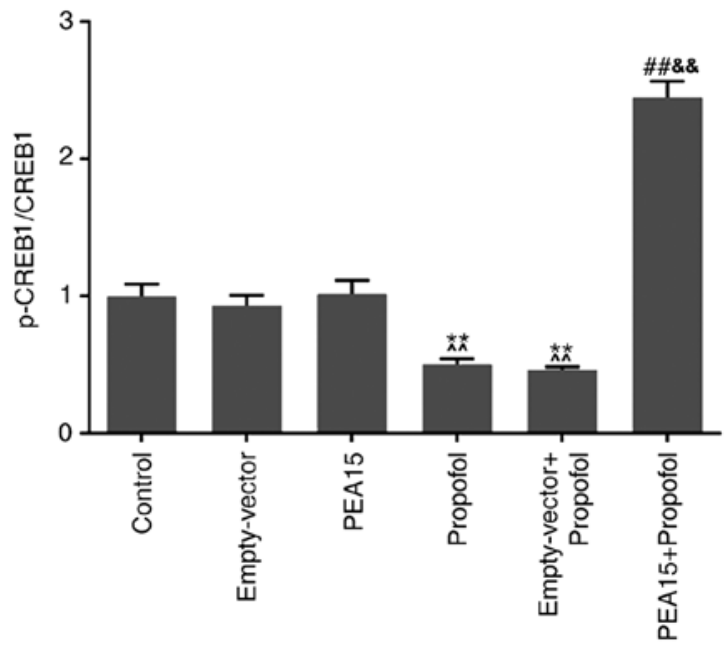

Figure 6. PEA15 and propofol regulate ERK-CREB-RSK2 signaling in hippocampal neurons. (A) Protein expression levels of p-ERK1/2, ERK1/2, RSK2, p-CREB1 and CREB1 were examined by western blot analysis. Densitometric analysis of the protein expression levels of (B) RSK2, and the (C) p-ERK1/2/ERK1/2 ratio and (D) $\mathrm{p}$-CREB1/CREB1 ratio. ${ }^{* *} \mathrm{P}<0.01$ vs. control; ${ }^{\wedge} \mathrm{P}<0.01$ vs. empty-vector; ${ }^{\# /} \mathrm{P}<0.01$ vs. propofol; \&\& $\mathrm{P}<0.01$ vs. empty-vector + propofol. $\mathrm{PEA} 15$, phosphoprotein enriched in astrocytes 15; ERK, extracellular signal-regulated kinases; CREB1, cAMP responsive element binding protein 1; RSK2, ribosomal S6 kinase 2; p-, phosphorylated.

neurons. In the present study, it was hypothesized that the mechanisms underlying the PEA15 and propofol effects on the proliferation and apoptosis of hippocampal neurons may be associated with the ERK-CREB pathway. The present results suggested that propofol significantly repressed the phosphorylation levels of ERK1/2 and CREB1, and decreased the protein expression level of RSK2. However, overexpression of PEA15 was able to revert the protein expression levels of p-ERK1/2, p-CREB1 and RSK2, which were suppressed by propofol. The present results suggested that PEA15 overexpression promoted the ERK-CREB-RSK2 signaling pathway. Collectively, the present results suggested that the cell damage caused by propofol was attenuated by PEA15 overexpression. However, testing the effects of PEA15 knockdown may further aid the understanding of the role of PEA15 in neuronal injury.

In conclusion, the present results suggested that PEA15 ameliorated propofol-induced hippocampal nerve damage by promoting cell proliferation, and PEA15 was able to decrease cell apoptosis by upregulating the ERK-CREB-RSK2 signaling pathway. The present study suggested that PEA15 may represent a potential therapeutic agent to treat human diseases characterized by neuronal damage.

\section{Acknowledgements}

Not applicable.

\section{Funding}

No funding was received.

\section{Availability of data and materials}

The datasets used and/or analyzed during the current study are available from the corresponding author on reasonable request.

\section{Authors' contributions}

FX provided a substantial contribution to conception and design of the present study. QL and ZC were involved in data acquisition, analysis and interpretation. ZC and FX were involved in 
drafting the article or critically revising it for important intellectual content. All authors gave final approval of the version to be published. All authors agreed to be accountable for all aspects of the work, and in ensuring that questions related to the accuracy or integrity of the work are appropriately investigated and resolved.

\section{Ethics approval and consent to participate}

The animal experimental research was approved by the Ethics Committee of The First People's Hospital of Changzhou, The Third Affiliated Hospital of Soochow University (Changzhou, China)

\section{Patient consent for publication}

Not applicable.

\section{Competing interests}

The authors declare that they have no competing interests.

\section{References}

1. King MR and Feldman JM: Optimal management of apparatus dead space in the anesthetized infant. Paediatr Anaesth 27 1185-1192, 2017.

2. Kotwani MB and Malde AD: Comparison of maintenance, emergence and recovery characteristics of sevoflurane and desflurane in pediatric ambulatory surgery. J Anaesthesiol Clin Pharmacol 33: 503-508, 2017.

3. Wang CH, Luo J, Li J, Zhang JZ, Huang SY, Shao W and Ma HS: Efficacy of inhalational sevoflurane anesthesia induction on inhibiting the stress response to endotracheal intubation in children with congenital heart disease. Eur Rev Med Pharmacol Sci 22: 1113-1117, 2018.

4. Chimelli L, Moura Pone S, Avvad-Portari E, Farias Meira Vasconcelos Z, Araújo Zin A, Prado Cunha D, Raposo Thompson N, Lopes Moreira ME, Wiley CA and da Silva Pone MV: Persistence of zika virus after birth: Clinical, virological, neuroimaging, and neuropathological documentation in a 5-month infant with congenital zika syndrome. J Neuropathol Exp Neurol 77: 193-198, 2018.

5. Hannagan T, Nieder A, Viswanathan P and Dehaene S: A random-matrix theory of the number sense. Philos Trans R Soc Lond B Biol Sci 373: 20170253, 2017.

6. Subedi L, Huang H, Pant A, Westgate PM, Bada HS, Bauer JA, Giannone PJ and Sithisarn T: Plasma brain-derived neurotrophic factor levels in newborn infants with neonatal abstinence syndrome. Front Pediatr 5: 238, 2017.

7. Backeljauw B, Holland SK, Altaye M and Loepke AW: Cognition and brain structure following early childhood surgery with anesthesia. Pediatrics 136: e1-12, 2015.

8. Sun L: Early childhood general anaesthesia exposure and neurocognitive development. Br J Anaesth 105 (Suppl 1): i61-i68, 2010.

9. Coleman K, Robertson ND, Dissen GA, Neuringer MD, Martin LD, Cuzon Carlson VC, Kroenke C, Fair D and Brambrink AM: Isoflurane anesthesia has long-term consequences on motor and behavioral development in infant rhesus macaques. Anesthesiology 126: 74-84, 2017.

10. El-Dib M and Soul JS: The use of phenobarbital and other anti-seizure drugs in newborns. Semin Fetal Neonatal Med 22: 321-327, 2017.

11. Hu L, Pan J, Zhang S, Yu J, He K, Shu S and Wang R: Propofol in combination with remifentanil for cesarean section: Placental transfer and effect on mothers and newborns at different induction to delivery intervals. Taiwan J Obstet Gynecol 56: 521-526, 2017.

12. Razlevice I, Rugyte DC, Strumylaite L and Macas A: Assessment of risk factors for cerebral oxygen desaturation during neonatal and infant general anesthesia: An observational, prospective study. BMC Anesthesiol 16: 107, 2016.
13. Cattano D, Young C, Straiko MM and Olney JW: Subanesthetic doses of propofol induce neuroapoptosis in the infant mouse brain. Anesth Analg 106: 1712-1714, 2008.

14. Creeley C, Dikranian K, Dissen G, Martin L, Olney J and Brambrink A: Propofol-induced apoptosis of neurones and oligodendrocytes in fetal and neonatal rhesus macaque brain. $\mathrm{Br}$ J Anaesth 110 (Suppl 1): i29-i38, 2013.

15. Pearn ML, Hu Y, Niesman IR, Patel HH, Drummond JC, Roth DM, Akassoglou K, Patel PM and Head BP: Propofol neurotoxicity is mediated by $\mathrm{p} 75$ neurotrophin receptor activation. Anesthesiology 116: 352-361, 2012.

16. Yu D, Jiang Y, Gao J, Liu B and Chen P: Repeated exposure to propofol potentiates neuroapoptosis and long-term behavioral deficits in neonatal rats. Neurosci Lett 534: 41-46, 2013.

17. Kahraman S, Zup SL, McCarthy MM and Fiskum G: GABAergic mechanism of propofol toxicity in immature neurons. J Neurosurg Anesthesiol 20: 233-240, 2008.

18. Sall JW, Stratmann G, Leong J, Woodward E and Bickler PE: Propofol at clinically relevant concentrations increases neuronal differentiation but is not toxic to hippocampal neural precursor cells in vitro. Anesthesiology 117: 1080-1090, 2012.

19. Spahr-Schopfer I, Vutskits L, Toni N, Buchs PA, Parisi L and Muller D: Differential neurotoxic effects of propofol on dissociated cortical cells and organotypic hippocampal cultures. Anesthesiology 92: 1408-1417, 2000.

20. Danziger N, Yokoyama M, Jay T, Cordier J, Glowinski J and Chneiweiss H: Cellular expression, developmental regulation, and phylogenic conservation of PEA-15, the astrocytic major phosphoprotein and protein kinase C substrate. J Neurochem 64: 1016-1025, 1995.

21. Greig FH and Nixon GF: Phosphoprotein enriched in astrocytes (PEA)-15: A potential therapeutic target in multiple disease states. Pharmacol Ther 143: 265-274, 2014.

22. Ahn EH, Kim DW, Shin MJ, Kim HR, Kim SM, Woo SJ, Eom SA, Jo HS, Kim DS, Cho SW, et al: PEP-1-PEA-15 protects against toxin-induced neuronal damage in a mouse model of Parkinson's disease. Biochim Biophys Acta 1840: 1686-1700, 2014.

23. Greig FH, Kennedy S, Gibson G, Ramos JW and Nixon GF: PEA-15 (Phosphoprotein Enriched in Astrocytes 15) is a protective mediator in the vasculature and is regulated during neointimal hyperplasia. J Am Heart Assoc 6: e006936, 2017.

24. Mohammed HN, Pickard MR and Mourtada-Maarabouni M: The protein phosphatase 4-PEA15 axis regulates the survival of breast cancer cells. Cell Signal 28: 1389-1400, 2016.

25. Sung JH and Koh PO: Hyperglycemia aggravates decreases of PEA-15 and its two phosphorylated forms in cerebral ischemia. J Vet Med Sci 79: 654-660, 2017.

26. Wei Y: On the quest of cellular functions of PEA-15 and the therapeutic opportunities. Pharmaceuticals (Basel) 8: 455-473, 2015.

27. Huang JY, Wang K, Vermehren-Schmaedick A, Adelman JP and Cohen MS: PARP6 is a regulator of hippocampal dendritic morphogenesis. Sci Rep 6: 18512, 2016.

28. Tang JS, Xie BX, Bian XL, Xue Y, Wei NN, Zhou JH, Hao YC, Li G, Zhang LR and Wang KW: Identification and in vitro pharmacological characterization of a novel and selective $\alpha 7$ nicotinic acetylcholine receptor agonist, Br-IQ17B. Acta Pharmacol Sin 36: 800-812, 2015.

29. Hsu HT, Tseng YT, Hsu YY, Cheng KI, Chou SH and Lo YC: Propofol attenuates lipopolysaccharide-induced reactive oxygen species production through activation of $\mathrm{Nrf} 2 / \mathrm{GSH}$ and suppression of NADPH oxidase in human alveolar epithelial cells. Inflammation 38: 415-423, 2015.

30. Xia JH, Shi XY, Xu ZD, Liu G and Wang YH: In vitro effects of propofol on apoptosis and Bax expression induced by TNF- $\alpha$ in mouse spinal cord neurons. Acad J Sec Military Med Univ 27: 169-172, 2006.

31. Livak KJ and Schmittgen TD: Analysis of relative gene expression data using real-time quantitative PCR and the 2(-Delta Delta C(T)) method. Methods 25: 402-408, 2001.

32. Facci L and Skaper SD: Culture of rodent cortical, hippocampal, and striatal neurons. Methods Mol Biol 1727: 39-47, 2018.

33. Rivera-Carvantes MC, Jarero-Basulto JJ, Feria-Velasco AI, Beas-Zárate C, Navarro-Meza M, González-López MB, Gudiño-Cabrera G and García-Rodríguez JC: Changes in the expression level of MAPK pathway components induced by monosodium glutamate-administration produce neuronal death in the hippocampus from neonatal rats. Neuroscience 365: 57-69, 2017.

34. Eibl JK, Strasser BC and Ross GM: Structural, biological, and pharmacological strategies for the inhibition of nerve growth factor. Neurochem Int 61: 1266-1275, 2012. 
35. Liang C, Du F, Cang J and Xue Z: Pink1 attenuates propofol-induced apoptosis and oxidative stress in developing neurons. J Anesth 32: 62-69, 2018

36. Monni L, Ghezzi F, Corsini S and Nistri A: Neurotoxicity of propofol on rat hypoglossal motoneurons in vitro. Neurosci Lett 655: 95-100, 2017.

37. Yan Y, Qiao S, Kikuchi C, Zaja I, Logan S, Jiang C, Arzua T and Bai X: Propofol induces apoptosis of neurons but not astrocytes, oligodendrocytes, or neural stem cells in the neonatal mouse hippocampus. Brain Sci 7: E130, 2017.

38. Liu Y, Yan Y, Inagaki Y, Logan S, Bosnjak ZJ and Bai X: Insufficient astrocyte-derived brain-derived neurotrophic factor contributes to propofol-induced neuron death through Akt/glycogen synthase kinase $3 \beta /$ mitochondrial fission pathway. Anesth Analg 125: 241-254, 2017.

39. Lv J, Wei Y, Chen Y, Zhang X, Gong Z, Jiang Y, Gong Q, Zhou L, Wang $\mathrm{H}$ and $\mathrm{Xie} \mathrm{Y}$ : Dexmedetomidine attenuates propofol-induce neuroapoptosis partly via the activation of the PI3k/Akt/GSK3 $\beta$ pathway in the hippocampus of neonatal rats. Environ Toxicol Pharmacol 52: 121-128, 2017

40. Huang Q, Voloudakis G, Ren Y, Yoon Y, Zhang E, Kajiwara Y, Shao Z, Xuan Z, Lebedev D, Georgakopoulos A and Robakis NK: Presenilin $1 / \gamma$-secretase protects neurons from glucose deprivation-induced death by regulating miR-212 and PEA15. FASEB J 32: 243-253, 2018
41. Shahin S, Banerjee S, Swarup V, Singh SP and Chaturvedi CM: From the cover: $2.45-\mathrm{GHz}$ microwave radiation impairs hippocampal learning and spatial memory: Involvement of local stress mechanism-induced suppression of iGluR/ERK/CREB signaling. Toxicol Sci 161: 349-374, 2018.

42. Yi LT, Li J, Liu BB, Luo L, Liu Q and Geng D: BDNF-ERK-CREB signalling mediates the role of miR-132 in the regulation of the effects of oleanolic acid in male mice. J Psychiatry Neurosci 39: 348-359, 2014.

43. Zuo H, Lin T, Wang D, Peng R, Wang S, Gao Y, Xu X, Zhao L, Wang $S$ and $\mathrm{Su} Z$ : RKIP regulates neural cell apoptosis induced by exposure to microwave radiation partly through the MEK/ERK/CREB pathway. Mol Neurobiol 51: 1520-1529, 2015.

44. Kaphzan H, Doron G and Rosenblum K: Co-application of NMDA and dopamine-induced rapid translation of RSK2 in the mature hippocampus. J Neurochem 103: 388-399, 2007.

45. Kozinn J, Mao L, Arora A, Yang L, Fibuch EE and Wang JQ: Inhibition of glutamatergic activation of extracellular signal-regulated protein kinases in hippocampal neurons by the intravenous anesthetic propofol. Anesthesiology 105: 1182-1191, 2006.

(1) (9) This work is licensed under a Creative Commons Attribution-NonCommercial-NoDerivatives 4.0 International (CC BY-NC-ND 4.0) License. 